\title{
Evaluation of Child Health by Basic Indicators of Health: Historical Series 2005-2014
}

\section{Tainara Lôrena dos Santos Ferreira, Héllyda de Souza Bezerra, Julliane Tamara Araújo de Melo, Thaiza Teixeira Xavier Nobre, Fábia Barbosa de Andrade}

The faculty of Health Sciences of Trairi (FACISA), Federal University of Rio Grande do Norte (UFRN), Santa Cruz, Brazil

Email: tainara_lorena@hotmail.com, hellydasbezerra@hotmail.com,tamara_bio@yahoo.com.br, thaizax@hotmail.com, fabiabarbosabr@yahoo.com.br

How to cite this paper: dos Santos Ferreira, T.L., de Souza Bezerra, H., de Melo, J.T.A., Nobre, T.T.X. and de Andrade, F.B. (2018) Evaluation of Child Health by Basic Indicators of Health: Historical Series 2005-2014. Health, 10, 289-299.

https://doi.org/10.4236/health.2018.103023

Received: July 31, 2017

Accepted: March 13, 2018

Published: March 16, 2018

Copyright $\odot 2018$ by authors and Scientific Research Publishing Inc. This work is licensed under the Creative Commons Attribution International License (CC BY 4.0).

http://creativecommons.org/licenses/by/4.0/

(c) (i) Open Access

\begin{abstract}
The continuous assessment of child health services generates knowledge about the real needs of health services and actions in order to achieve better results and indicators. Thus, this study proposes to analyze child health indicators, based on the information systems of health services. This is a descriptive, ecological epidemiological study carried out using secondary data from the following information systems: Information System on Live Births and Mortality Information System, in a historical series of ten years (2005-2014) of the state of Rio Grande do Norte and its health micro regions. It was observed a decrease in infant, neonatal, preterm, late neonatal and postnatal mortality coefficients when compared to the first and last year of the observed period, as well as the concentration of these in micro-regions of health. There was also a positive association between the early neonatal component and infant death. In this perspective, it is important to evaluate the quality of prenatal care, childbirth, puerperium, the first week of integral health and follow-up of the child's growth and development, as well as to relate the socio-demographic conditions that may be associated with infant morbimortality. Therefore, the importance of situational health assessment studies for the effectiveness of care provided is highlighted, identifying weaknesses and monitoring the effectiveness of strategies.
\end{abstract}

\section{Keywords}

Child Health, Information Systems, Temporal Distribution, Evaluation Studies 


\section{Introduction}

Evaluation studies in the health of the child have gained ample highlights, as they boost the dynamics of planning, monitoring and identifying the weaknesses and potential of actions, health services and, consequently, policies and health programs. According to authors [1], it has the fundamental sense of converting concepts into strategies, criteria and measurement patterns, in order to assist in decision-making and subsidize services improvements.

In this scenario, assessing the children's population becomes fundamental to ensuring the quality of care, directing and effectiveness of interventions from coverage analysis, access, equity, technical quality and results obtained, so that there is continuous monitoring, observing the growth and development integrally, with the aim of promoting the health of the infant population and preventing aggravations. It is emphasized [2] the importance of monitoring coverage measures, given the rapid response to programme policies and interventions of impact measures (quoting, mortality, morbidity, fertility, nutritional status).

Thus, from the health information systems, indicators have been increasingly observed on the morbidity and mortality of the children of the Brazil, as the mortality coefficients that are shown as an indicator of interest to the World Health Organization and Ministry of Health, for estimating the risk of death, generally reflecting on the conditions of development and the access and quality of attention to maternal and child health. In Brazil, regarding the evaluation of infant mortality, the tendency of decline has been perceived, although it still possesses high values, possibly related to improving the quality of life, basic sanitation and social determinants of health.

The Child Health Care Program (PAISC) is created by the Ministry of Health to ensure children a quality income and reduce morbidity and mortality in the age group 0 to 5 years, with specific care: accompanying growth and development as a methodology for organizing child assistance; promoting breastfeeding and guiding feeding in the first year of life; increase the levels of vaccination coverage according to the technical standards of the Ministry of Health; to identify early pathological processes, fostering timely diagnosis and treatment, and promoting education, highlighting the family's importance in child care activities [3].

In the framework of child health services, the quality of health care and the effectiveness of the assistance of the actions and services rendered to this population, strengthening the proposal for health surveillance of the child, which is an operational guideline aimed at reducing the morbidity and mortality, enabling the range of children to be proposed targets at national and international level, seeking better child health results.

The monitoring of the growth and development of the child's health is the structuring axis of the care lines of the full attention to the child's health and enables the identification of special needs that deserve timely approach [4]. The attention to the child's health represents a milestone when proposing the at- 
tending to infant health in the context of paid care, and its adoption is shown as an important step for the recognition of the rights of the child, which points to the commitment to provide quality of life for this [5].

Through monitoring of actions and results and the continuing evaluation of health services, you can know the real needs of the service, the quality of assistance provided and the satisfaction of users, fundamental factors for the adequacy of public health policies and implementation of actions, with stimulating the positive reach of child health indicators. In this perspective, this study aims to analyze the health indicators of the child in the state of Rio Grande do Norte and its health micro regions, based on health services information systems, in a historical-temporal series, comprising the years of 2005 to 2014 .

\section{Methodology}

It is an epidemiological, descriptive, ecological study of a time series, carried out using secondary data from the following information systems: Information System on Live Births (SINASC) and Mortality Information System (SIM), in a historical series of the last ten years (2005-2014) on the state of Rio Grande do Norte and its health microregions.

For the authors [6], the descriptive study proposes to observe record, analyze and correlate facts or phenomena (variables) without manipulating them, in order to discover, with maximum possible precision, the frequency with which a phenomenon occurs, their relationship and connection with others, their nature and characteristics. In addition, it seeks to know the different situations and relationships in which they occur, both in the individual taken alone and in more complex groups and communities.

Rio Grande do Norte is the 10th most populous Brazilian Federation and the 16th most populous, with 167 municipalities and is divided into eight Health Regions (RS). According to the State Health Plan 2012-2015 [7], regarding the population distribution by RS, it is evident that the 7th RS (Metropolitan), constituted by five municipalities (Natal, Extremoz, Macaíba, Parnamirim and São Gonçalo do Amarante), is the one with the largest contingent population, equivalent to $1,187,899$ inhabitants, corresponding to $37.5 \%$ of the total population of the state of the RN, with its resident population concentrated in the Capital (Natal) and in Parnamirim, the second Population of this Region. The second RS (West-Mossoró), which includes 15 municipalities, is the second most populous in the state, with 448,904 inhabitants, concentrating $14.17 \%$ of the total population of the RN. Next, there is the 1st RS (South and Agreste Coastal-São José de Mipibu), with 351,502 inhabitants, distributed among the 27 municipalities that comprise it; The 3rd RS (Mato Grande and Salineira-João Câmara), with 25 municipalities and 312,919 inhabitants; The 4th RS (Seridó-Caicó), formed by 25 municipalities, with 295,726 inhabitants; The 6th RS (Alto Oeste-Pau dos Ferros) that brings together 36 municipalities, with 230,042 inhab-itants; The 5th RS (Trairi and Potengi-Santa Cruz), with 21 municipalities and 185,719 
inhabitants; And the 8th RS (Açu Valley), composed of 13 municipalities, with 155,316 inhabitants.

As this is an ecological study of time series in which the same area will be studied in the period from 2005 to 2014, the population involved will be the ones that compose the secondary data, obtained through SINASC and SIM. The procedures adopted for the data collection took place through the execution of several steps, namely: contact with the Municipal Health Department and V Regional Public Health Unit to communicate the objectives of the research and obtain access permission to the databases of the SIM and the SINASC of the state of Rio Grande do Norte, in addition to using the information extracted from the national public domain database of the Ministry of Health entitled DATASUS-Department of Information Technology of SUS. The data did not need to be cleaned, however, they were organized, stored and analyzed in the Statistical Package for Social Science (SPSS), version 22.0, serial number: 10101141047. Data were analyzed for mortality coefficients as well As measured by central tendency, student $t$ test and Odds Ratio, adopting a 95\% Confidence Interval, and a significance level of $5 \%$ for all tests. For the calculation of mortality coefficients, it was considered:

$$
\begin{aligned}
& \text { CMI }=\frac{\text { Number of deaths of residents under one year of age }}{\text { Number of live births of resident mothers }} \times 1000 \\
& \text { CMNP }=\frac{\text { Number of deaths of residents from } 0 \text { to } 6 \text { days of life }}{\text { Number of live births of resident mothers }} \times 1000 \\
& \text { CMNT }=\frac{\text { Number of deaths of residents from } 7 \text { to } 27 \text { days of life }}{\text { Number of live births of resident mothers }} \times 1000 \\
& \mathrm{CMPN}=\frac{\text { Number of deaths of residents from } 28 \text { to } 364 \text { days of age }}{\text { Number of live births of resident mothers }} \times 1000
\end{aligned}
$$

For the projection of the spatial distribution of the mortality coefficients observed in the state of Rio Grande do Norte, by health regions and construction of the maps, we used TabWin32-version 4.1.1, which is a program developed by DATASUS with The objective of assisting in the planning and programming of services and consequently in the evaluation and decision-making through the construction and application of epidemiological characteristics and demographic aspects. The graphical data was obtained from the DATASUS health region map.

Considering the ethical aspects of the research, this study was exempt from the appreciation of the Research Ethics Committee, because it uses only secondary and public domain data.

\section{Results}

The use of secondary data has been widely used in the systematic evaluation of infant mortality in health services, which comes from official information systems such as SIM and SINASC, mainly due to the possibility of linking these databases [8]. These systems of epidemiological rationality have gained relevance 
because they have essential data for the calculation of health monitoring indicators and evaluation of programmatic actions [9]. Thus, in this study, we observed the data referring to the 167 municipalities in the state of Rio Grande do Norte, subdivided into eight RS.

As regards the average of the (CMI) (Infant mortality coefficient), (CMNP) (the coefficient of early neonatal mortality), (CMNT) (the late neonatal mortality rate) and (CMPN) (the post-neonatal mortality coefficient), Table 1, it was observed that These coefficients decrease when compared to the years of 2005 and 2014, where the highest averages were observed in 2005, with 16.45 relative to the infant mortality coefficient; In 2005, with 8.85 referring to the coefficient of early neonatal mortality; In 2012, with 3.19 higher than the late neonatal mortality coefficient and, in 2005, for the post-neonatal mortality coefficient, the mean 5.66. Throughout the observed period, $\mathrm{p}<0.05$ was found in the t-test, being statistically significant.

Regarding the distribution of average infant and fetal death number (Graph 1) by maternal residence in the state of the $\mathrm{RN}$, it is observed that it has been declining during the period observed when, in 2005, the average infant death corresponded to 6.33 and fetal average was presented in 3.49. In the last year of the observed period, it reveals an infant death average corresponding to 4.90 and fetal 2.98. It is also emphasized that fluctuations between the analysed deaths, presenting declines with elevations in subsequent years. In the whole time series, check for $\mathrm{p}<0.05$ on the T-Test.

The spatial distribution by coefficients in maps of Figure 1 shows that the largest CMI (under one year of age) is concentrated in the regions of Caicó-4a RS (17.75), followed by Açu-8 $8^{\mathrm{a}}$ RS (15.10), Mossoró-2 ${ }^{\mathrm{a}}$ RS 14.75) and Santa Cruz- $5^{\mathrm{a}} \mathrm{RS}$ (14.05). It is observed that the concentration of the greatest gatherings, like CMNP follows the concentration of MIC.

As for the CMNT, on time series observed, presents higher concentrations in the Açuu $-8^{\text {a }}$ RS (2.3), followed by Metropolitan-7a RS (2.05), Caicó-4a RS (2.00), Brazil $-2^{\mathrm{a}}$ RS (1.9) and Pau dos Ferros-6 $6^{\mathrm{a}}$ RS (1.9). The CMPN coefficient, observed, it may be noted in João Câmara concentrations-3 $3^{a}$ RS (6.0), followed by São José de Mipibu-1 ${ }^{\text {a }}$ RS (4.9), Santa Cruz-5 $5^{\text {a }}$ RS (4.4) and Caicó-4 $4^{\text {a }}$ RS (4.3), respectively.

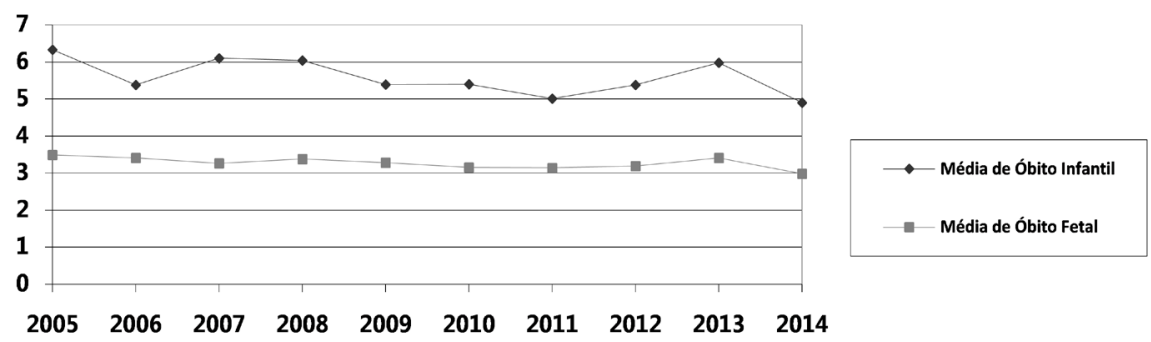

Graph 1. Distribution of means of infant and fetal death by maternal residence in the historical series 2005-2014, state of Rio Grande do Norte, Brazil, 2016. 
Table 1. Averages of neonatal and infant mortality coefficients in the historic temporal series 2005-2014, state of Rio Grande do Norte, Brazil, 2016.

\begin{tabular}{|c|c|c|c|c|c|c|c|c|c|c|c|c|}
\hline \multirow{2}{*}{ YEAR } & \multicolumn{3}{|c|}{$\begin{array}{l}\text { Infant mortality } \\
\text { coefficient }\end{array}$} & \multicolumn{3}{|c|}{$\begin{array}{c}\text { Coefficient of Early Neonatal } \\
\text { Mortality }\end{array}$} & \multicolumn{3}{|c|}{$\begin{array}{c}\text { Coefficient of Late Neonatal } \\
\text { Mortality }\end{array}$} & \multicolumn{3}{|c|}{$\begin{array}{c}\text { Coefficient of } \\
\text { Post-neonatal Mortality }\end{array}$} \\
\hline & Average & $\mathrm{DP}$ & $\mathrm{p}$ & Average & $\mathrm{DP}$ & $\mathrm{p}$ & Average & $\mathrm{DP}$ & $\mathrm{p}$ & Average & $\mathrm{DP}$ & $\mathrm{p}$ \\
\hline 2005 & 16.4587 & 13.68 & $<0.01$ & 8.8599 & 10.47 & $<0.01$ & 1.9305 & 4.27 & $<0.01$ & 5.6689 & 7.63 & $<0.01$ \\
\hline 2006 & 15.7006 & 16.55 & $<0.01$ & 8.8353 & 14.85 & $<0.01$ & 1.3395 & 3.89 & $<0.01$ & 5.5240 & 8.22 & $<0.01$ \\
\hline 2007 & 14.5066 & 13.14 & $<0.01$ & 8.2084 & 9.73 & $<0.01$ & 1.3108 & 3.22 & $<0.01$ & 4.9874 & 8.36 & $<0.01$ \\
\hline 2008 & 13.2521 & 13.94 & $<0.01$ & 7.4066 & 11.29 & $<0.01$ & 1.8365 & 4.53 & $<0.01$ & 4.0084 & 5.90 & $<0.01$ \\
\hline 2009 & 13.3665 & 12.48 & $<0.01$ & 7.1162 & 9.60 & $<0.01$ & 2.1425 & 5.69 & $<0.01$ & 4.1042 & 7.04 & $<0.01$ \\
\hline 2010 & 13.5455 & 12.29 & $<0.01$ & 7.6072 & 9.03 & $<0.01$ & 2.4347 & 5.88 & $<0.01$ & 3.5036 & 5.68 & $<0.01$ \\
\hline 2011 & 14.1928 & 13.38 & $<0.01$ & 7.5749 & 9.95 & $<0.01$ & 2.0671 & 5.18 & $<0.01$ & 4.5545 & 7.07 & $<0.01$ \\
\hline 2012 & 14.1928 & 13.44 & $<0.01$ & 6.9856 & 9.16 & $<0.01$ & 3.1904 & 7.27 & $<0.01$ & 4.0168 & 6.31 & $<0.01$ \\
\hline 2013 & 14.8557 & 14.82 & $<0.01$ & 7.8790 & 9.93 & $<0.01$ & 2.6246 & 5.99 & $<0.01$ & 4.3539 & 9.24 & $<0.01$ \\
\hline 2014 & 14.4269 & 14.10 & $<0.01$ & 8.2275 & 10.26 & $<0.01$ & 1.4749 & 3.54 & $<0.01$ & 4.7251 & 8.30 & $<0.01$ \\
\hline
\end{tabular}

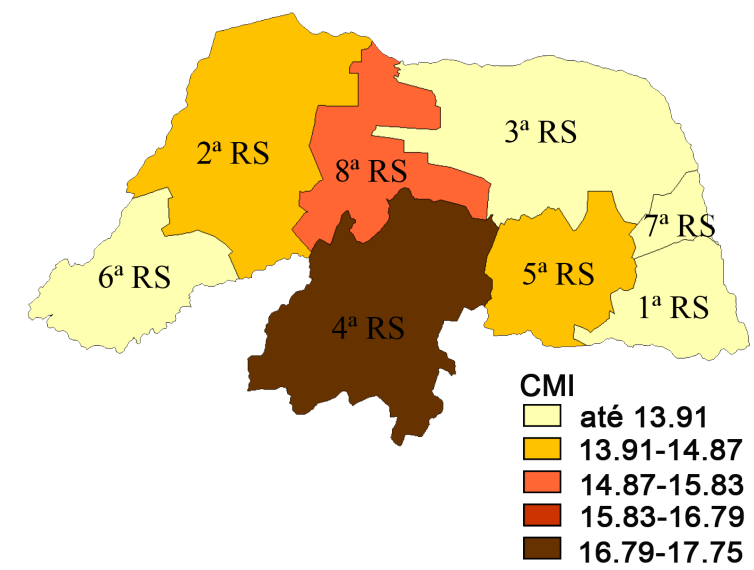

Infant mortality coefficient

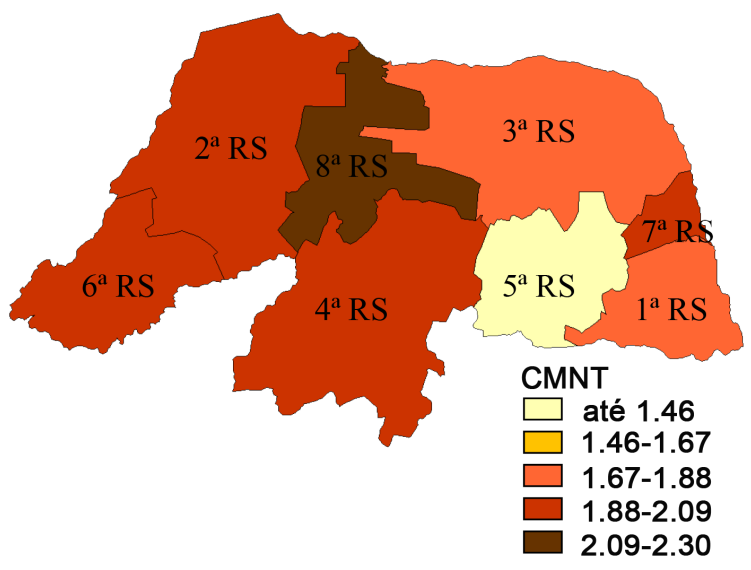

Coefficient of Late Neonatal Mortality

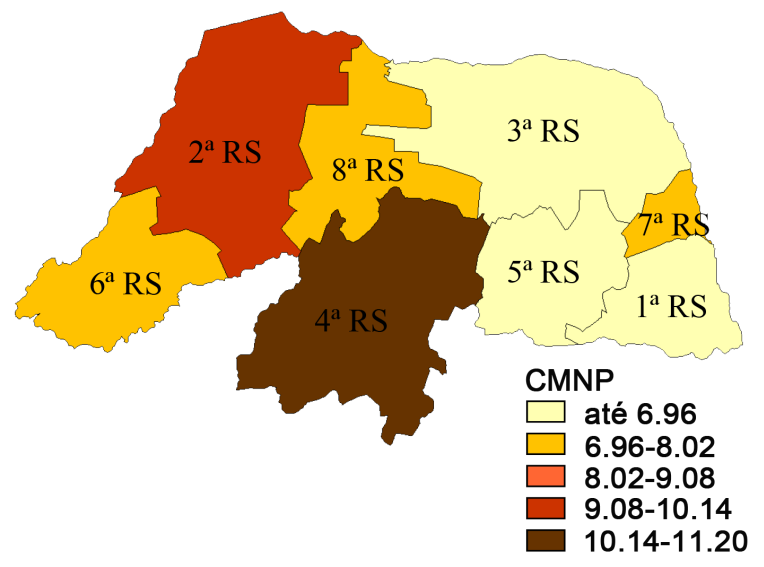

Coefficient of Early Neonatal Mortality

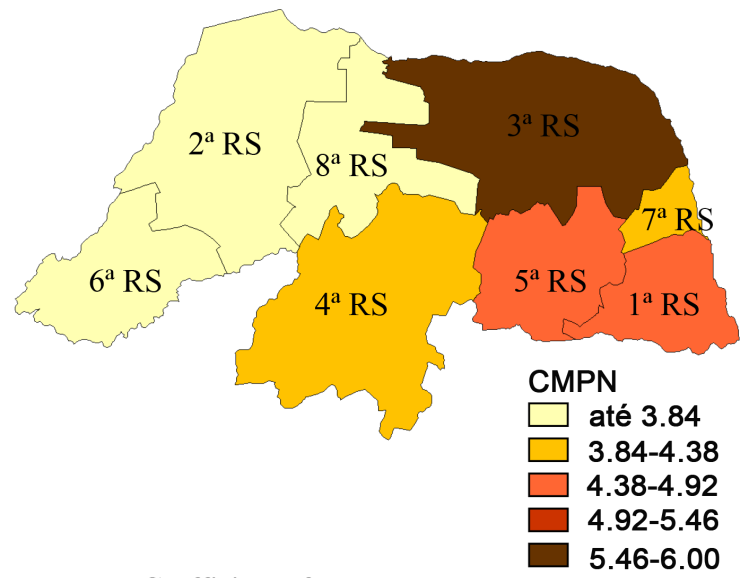

Coefficient of Post-neonatal Mortality

Figure 1. Spatial distribution of coefficients of the historical-temporal series 2005-2014, state of Rio Grande do Norte, Brazil, 2016. 
The calculation of OR, Crude Product Ratio, Relative Risk Estimate or Chance Ratio does not imply a cause and effect relationship, only suggest that there is an association. Thus, from these data (Table 2), a strong association between infant mortality and the early neonatal component is observed. In the observed period, the greatest association occurs in the last year of the time series when the early neonatal component corresponds to 1.41, with greater chances than in another component of infant mortality if presented with an increase of 0.14 when compared to the first year of the Period.

\section{Discussions}

In the present study, it was observed that the mortality coefficients have declined when compared to the first (2005) and the last (2014) year of the observed period, Table 1. Only the late neonatal component had a higher coefficient in 2012. In the However, in general, mortality coefficients show a decreasing trend. These results follow what has been observed in the country, considering that, in Brazil, there is a decrease in infant mortality. However, a large number of child mortality can still be avoided through access to health services and adequate and skilled care.

Taking into account the Guidelines, Objectives, Targets, and Indicators for the last two years (2013-2014), a goal of 14.0 deaths per 1000 live births is reached. However, 14.85 and 14.42 are observed as coefficients of infant mortality in the last years, respectively.

Infant mortality consists of two distinct periods, formed by different causal factors, with varying importance depending on the epidemiological situation of the area under analysis. The first period, called neonatal infant mortality,

Table 2. Number of infant and neonatal deaths, Odds Ratio (OR), in the historical-temporal series 2005-2014, state of Rio Grande do Norte, Brazil, 2016.

\begin{tabular}{cccc}
\hline YEAR & $\begin{array}{c}\text { Deaths in children under } \\
\text { one year } \\
\text { (Infant Mortality) }\end{array}$ & $\begin{array}{c}\text { Deaths between 0 and 6 days of life } \\
\text { (Early Neonatal } \\
\text { Mortality) }\end{array}$ & $\begin{array}{c}\text { Odds } \\
\text { Ratio } \\
\text { (OR) }\end{array}$ \\
\hline 2005 & 851 & 477 & 1.27 \\
2006 & 701 & 384 & 1.21 \\
2007 & 758 & 417 & 1.22 \\
2008 & 712 & 401 & 1.28 \\
2009 & 641 & 364 & 1.31 \\
2010 & 631 & 356 & 1.29 \\
2011 & 623 & 350 & 1.28 \\
2012 & 656 & 350 & 1.14 \\
2013 & 675 & 361 & 1.14 \\
2014 & 617 & 362 & 1.41 \\
\hline
\end{tabular}


consists of the deaths occurring in the first days of life. It is subdivided into two parts, called early and late, respectively, at intervals of 0 to 6 days and 7 to 27 days of life. In this period, the endogenous causes of death, mainly represented by congenital anomalies and perinatal conditions, are highlighted [10].

Authors [11] [12] argue that the early neonatal component of infant mortality, along with its causes and risk factors, is a health alert event because it influences the quality of the health services offered to the population and because it involves several Aspects, such as trained human resources and available technology. For these, death in the first days of life is related to the conjunction of biological, socioeconomic and care factors, the latter related mainly to the limitations in attention to the pregnant woman and the newborn.

In this assertion, what is observed in Table 2, in which a positive association between the early neonatal component and infant death was found by OR, shows that it corresponds to 1.41 higher odds than in another component of infant mortality for death in the last year of the observed period. It is noteworthy that such findings were also observed in other studies [13] [14] [15], to cite the study15 in Maracanaú, in the metropolitan region of Fortaleza/CE, Brazil, where 119 infant deaths were analyzed and, of these, $63,0 \%$ occurred in the neonatal period, $56.0 \%$ in the early period-up to 6 days of life. The second period of infant mortality refers to the deaths of children born alive, from 28 to 364 days of life, called post-neonatal or late infant mortality. During this period, the main causes of death are also considered avoidable and easy to intervene because they are more associated with poor conditions of basic sanitation and access to health care [16].

For some authors [17], the decrease in infant mortality is mainly due to the significant reduction of the post-neonatal component, which is more susceptible to preventive actions, such as vaccination campaigns, stimulation of breastfeeding and control of the Diarrheal disease. On the other hand, neonatal mortality results mainly from the relationships between biological, social and health care variables, so that their reduction becomes slower and more difficult.

The subdivision of the components into neonatal and post-neonatal allows evaluating the impact of the adopted measures in the control of infantile mortality [18]. The coverage and quality of prenatal and perinatal care are factors of great importance in the determination of neonatal infant mortality. As for the post-neonatal period, we present environmental and social factors, particularly those of a nutritional nature and infectious agents (exogenous causes), as determinants of mortality. Of particular note are gastroenteritis, respiratory infections and immune-preventable diseases [10].

In this study, from the spatialization, Figure 1, of the mean by coefficients in the period studied by micro-regions of health, it is observed that the largest CMI (in children under one-year-old) are concentrated in the 4th RS-Caicó, followed By Açu- $8^{\text {a }}$ RS, as well as the concentration of CMNP, which follows the health regions of greater concentration of the WCC. Regarding the CMNT, its highest concentrations are observed in Açu- $8^{\mathrm{a}}$ RS, followed by Metropolita- 
na $-7^{\text {a }}$ RS. Regarding the CMPN coefficient, in the observed period, one can notice concentration in João Câmara-3rd RS, followed by São José de Mipibu-1a RS and Santa Cruz- $5^{\text {a }}$ RS.

Thus, related to such neonatal component indicators, the maternal-infant health care network should be evaluated by regions where there are higher concentrations, such as Caicó- $4^{\text {a }} \mathrm{RS}, \mathrm{Açu}-8^{\mathrm{a}} \mathrm{RS}$, and Metropolitan $-7^{\mathrm{a}} \mathrm{RS}$, since Have a great influence on the access, quality of the services and the available technologies, being associated with the network of attention to the health.

As hypotheses for such indices, related to the post-neonatal component, the low average per capita income as a factor influencing death in the post-neonatal period is highlighted, since it has high death rates in the lower income health regions Average: João Câmara ( $\mathrm{R} \$ 295.03)$, São José do Mipibu ( $\mathrm{R}$ 293.54) and Santa Cruz ( $\$$ \$ 265.74). However, there is still its association with basic sanitation measures, access to health services and actions to prevent diseases and injuries [10] [16] [17].

On the distribution of the mean number of infant and fetal death by maternal residence in the state of Rio Grande do Norte, Graph 1, it is observed that it has declined, as observed by other authors [19]. Nonetheless, associations with risk factors should be verified in order to elaborate and evaluate strategic measures that may be carried out, aiming to achieve better results and decreases in fetal and infant deaths due to preventable causes.

The data reveal the need for family planning and prenatal care and quality of life activities in order to reduce the incidence since early identification of diseases and maternal-infant Physical, social and psychological, in relation to the environment where they are inserted.

A sustained concern with service delivery has been the quality of service delivery, so that everyone can develop methods to investigate possible need for change, evaluate old procedures, measure the quality of established processes, and indicate whether There is a logical connection between the various types of demands for services and processes that traditionally operate to meet, satisfy, and ensure the smooth functioning of all processes and organizational structures aimed at patient benefit. Evaluation in the organization of health services is absolutely essential as it contributes to the identification of strengths and weaknesses of the health system [10].

Thus, the assessment of child health services seeks the quality of health care and the effectiveness of the assistance of actions and services provided to this population, as well as strengthens the proposal of health surveillance of the child, in search of better health outcomes Child. Therefore, assessing the child population becomes important for ensuring the quality of care and for directing and affecting interventions, based on the analysis of coverage, access, equity, technical quality and results obtained.

\section{Conclusions}

The analysis of child health indicators in the state of Rio Grande do Norte and 
its health micro regions in the period from 2005 to 2014 showed a decreasing trend in infant mortality coefficients in the observed period. This same trend of decline has also been observed in the state of fetal death in the state. However, there are also decreasing periods followed by increasing periods in the time series.

The spatial distribution of the indicators observed in the studied regions shows that the high concentrations of infant, neonatal, early neonatal, late neonatal and post neonatal mortality indicate the urgency of local health surveys and investigations to confirm the hypothesis of factors that have influenced the deaths. The association between the odds ratio of the early neonatal component for infant death is also highlighted. The urgency of local health analyzes and researches to confirm the hypothesis of factors that have influenced the death. Here, the association perceived by an odds ratio of the early neonatal component for infant death is also highlighted.

As limitations of this study, the presence of underreporting of deaths and failure to complete the death certificate correctly are highlighted. Such facts may compromise the quality of the information acquired, as well as the analysis and subsequent hypotheses that may be suggested. Thus, from these observations, it is suggested to implement strategies, assessments and constant monitoring, in order to promote constant and adequate registration for the purpose of analysis of health situations that can be observed through the information systems.

Despite these limitations, the study points to the need for evaluations in the field of child health in the state of Rio Grande do Norte. In this perspective, it is important to evaluate the quality of prenatal care, childbirth, puerperium, the first week of integral health and follow-up of the child's growth and development, as well as to relate the socio-demographic conditions that may be associated with infant morbimortality. These measures provide the identification of weaknesses and the main problems associated with the situational analysis of perceived health and assist in health planning and management for better results.

After analyzing the important evaluative aspects for the municipalities and for the state module of Rio Grande do Norte, it is necessary to emphasize that health indicators should be in line with the goals and programs of health of the child established by the Public system in force in Brazil, called the Unified Health System (SUS).

\section{References}

[1] Esperidião, M.A. and Trad, L.A.B. (2006) User Satisfaction Rating: Theoretical-Conceptual Considerations. Cad Public Health, 22, 1267-1276.

[2] Requejo, J.H., Newby, H. and Bryce, J. (2013) Measuring Coverage in MNCH: Challenges and Opportunities in the Selection of Coverage Indicators for Global Monitoring. PLoS Medicine, 10, e1001416. https://doi.org/10.1371/journal.pmed.1001416

[3] Brazil, Health Ministry. (1984) Comprehensive Health Care for Children: Basic Ac- 
tions. Documentation Center of the Health Ministry, Brasília.

[4] (2010) Municipal Secretary of Health and Civil Defense. Sub-Secretariat for Promotion, Primary Care and Health Surveillance, Primary Care Superintendence, Coordination of Care Lines and Special Programs, Child Care Line. Rio de Janeiro (RJ).

[5] Erdmann, A.L. and Sousa, F.G.M. (2009) Caring for the Child in Primary Health Care: Attitudes of Health Professionals. Health World, 33, 150-160.

[6] Cervo, A.L. and Bervian, P.A. (1996) Scientific Methodology. 4th Edition, Makron Books, São Paulo.

[7] Secretaria de Estado da Public Health. (2013) Rio Grande Do Norte state govern. Coordinator of Planning and Control of Health Services. State Health Plan 2012-2015. Natal/RN, May.

[8] Mello-Jorge, M.H.P., Laurenti, R. and Gotlieb, S.L.D. (2007) Analysis of the Quality of Brazilian Vital Statistics: The Implementation Experience of SIM and SINASC. Collective Health Sciences, 12, 643-654.

[9] Frias, P.G., Szwarcwald, C.L. and Lira, P.I.C. (2011) Estimation of Infant Mortality in the Context of Decentralization of the Public Health System (SUS). Maternal Children Health Brazilian Magazine, 11, 463-470.

[10] Medronho, R.A., et al. (2009) Epidemiology. 2nd Edition, Atheneu, São Paulo.

[11] Lansky, S., França, E. and Leal, M.C. (2002) Perinatal Mortality and Avoidance: Literature Review. Public Health Magazine, 36, 759-772.

[12] Kolling, A.F. (2011) Epidemiological Profile of Infant Mortality in Sapiranga-RS, from 2006 to 2009. Master Thesis, Rio Grande So Sul Federal University, Recife.

[13] Souza, R.K.T. and Gotlieb, S.L.D. (1993) Probability of Dying in the First Year of Life in Urban Area in the South of Brazil. Public Health Magazine, 27, 445-454.

[14] Oliveira, E.F.V., Gama, S.G.N. and Silva, C.M.F.P. (2010) Adolescent Pregnancy and Other Risk Factors for Fetal and Infant Mortality No in Rio de Janeiro, Brasil. Cad Public Health, 26, 567-578.

[15] Silva, C.F., Leite, Á.J.M., Almeida, N.M.G.S. and Gondim, R.C. (2006) Risk Factors for Infant Mortality in a Municipality in Northeast Brazil: Linkage between Databases of Live Births and Infant Deaths-2000 to 2002. Revista Brasileira de Epidemiologia, 9, 69-80. https://doi.org/10.1590/S1415-790X2006000100009

[16] Caldeira, A.P., et al. (2005) Evolution of Infant Mortality from Preventable Causes, Belo Horizonte, 1984-1998. Annual Review of Public Health, 39, 67-74.

[17] Araújo, B.F., Bozzetti, M.C. and Tanaka, A.C.A. (2000) Early Neonatal Mortality in Caxias do Sul: A Coorte Study. Journal of Pediatrics, 76, 200-206. https://doi.org/10.2223/JPED.53

[18] Kerr-Pontes, L.R. and Rouquayrol, M.Z. (2003) Collective Health Measure. In: Rouquayrol, M.Z. and Almeida Filho, N., Eds., Epidemiology and Health, 6th Edition, MEDSI, Rio de Janeiro, 37-82.

[19] Jorge, M.H.P.M., Laurenti, R. and Gotlieb, S.L.D. (2007) Analysis of the Quality of Brazilian Vital Statistics: The Implementation Experience of SIM and SINASC. Collective Health Sciences, 12, 643-654. 